\title{
EFEITO DE NÍVEIS DE LISINA DIGESTÍVEL VERDADEIRA E PROTEÍNA BRUTA NA DIETA SOBRE PARÂMETROS MORFO-FISIOLÓGICOS E UTILIZAÇÃO DO NITROGÊNIO EM SUÍNOS NA FASE INICIAL ${ }^{1}$
}

\author{
Effect of levels of digestible lysine and crude protein in diets on the organs weight, \\ physiologic parameters, jejune morfometry and nitrogen utilization of the diets for piglets
}

\author{
Márcio Gilberto Zangeronimo², Elias Tadeu Fialho ${ }^{3}$, Luis David Solis Murgas ${ }^{4}$, José Augusto de Freitas Lima ${ }^{3}$, \\ Érika Viviane Heidenheich da Rocha ${ }^{5}$,Renata Ribeiro Alvarenga ${ }^{6}$
}

\begin{abstract}
RESUMO
Foi conduzido um experimento no Departamento de Zootecnia da Universidade Federal de Lavras para verificar a influência de diferentes níveis de proteína bruta (PB) e lisina digestível verdadeira (LISD) na dieta sobre peso de órgãos, parâmetros fisiológicos e utilização do nitrogênio $(\mathrm{N})$ de rações por leitões na fase inicial. Foram utilizados 80 suínos machos castrados e fêmeas (peso inicial = $9,1 \pm 1,2 \mathrm{~kg}$ e final $=21,5 \pm 4,8 \mathrm{~kg}$ ), mestiços (Landrace $\mathrm{x}$ Large White), desmamados aos 28 dias, alojados em grupos de dois na creche em um delineamento em blocos casualizados (DBC) no tempo, em um fatorial 2 x 4 (PB x LISD) com cinco repetições, durante 35 dias. As rações foram formuladas com dois níveis de PB (16 e 18\%) e quatro níveis de LISD $(0,7 ; 0,9 ; 1,1$ e $1,3 \%)$ com correção dos valores de metionina e treonina seguindo o conceito de proteína ideal. Ao final do experimento, um animal (unidade experimental) de cada tratamento foi sacrificado para mensuração do $\mathrm{pH}$ do conteúdo estomacal e cecal, peso relativo do fígado, pâncreas e rins e altura das vilosidades e profundidade das criptas do jejuno. No Experimento II, 32 suínos machos castrados (peso inicial = 25 $\pm 1,3 \mathrm{~kg}$ ), provenientes do experimento anterior, foram alojados individualmente em gaiolas de metabolismo (unidade experimental), em um DBC no tempo em fatorial 2 x 4(PB x LISD), com quatro repetições, para avaliar o N ingerido (NI), $\mathrm{N}$ absorvido (NA), $\mathrm{N}$ retido (NR), e relação NR/NA (\%). Não houve diferenças $(\mathrm{P}>0,05)$ para as variáveis de abate. No balanço de $\mathrm{N}$, houve efeito linear crescente $(\mathrm{P}<0,01)$ dos níveis de lisina para NI e efeito quadrático $(\mathrm{P}<0,01)$ para NR e NR/NA, que aumentaram até os níveis de 1,05 e 1,06\% LISD, respectivamente independente do nível de PB. Não houve diferenças $(\mathrm{P}>0,05)$ para NA. Conclui-se que os níveis de LISD e PB não afetam o peso dos órgãos, parâmetros fisiológicos e morfometria do jejuno, porém melhoram a assimilação do $\mathrm{N}$ em até $25 \%$ com $1,05 \%$ de LISD em rações com níveis reduzidos de PB.
\end{abstract}

Termos para indexação: Aminoácidos, fisiologia, nutrição, proteína ideal.

\begin{abstract}
It was conducted an experiment in the Department of Animal Science at Lavras Federal University in order to verify the influence of different crude protein levels (CP) and digestible lysine (DLys) in the diet on the organs weight, physiologic parameters and utilization of nitrogen in the diet for piglets. It was utilized a total of 83 barrows and females (initial weight $=9.1 \mathrm{~kg} \pm 1.2 \mathrm{~kg}$ and final weight $=21.5 \pm 4.8 \mathrm{~kg}$ ), crossbred (Landrace $\mathrm{x}$ Large White), weaned at 28 days old, allotted in groups of two in nursery in a randomized block design (RBD) in time, in $2 \times 4$ factorial scheme (CP x DLys), with five repetitions, during 35 days. The diets were formulated with two levels of CP (16 and $18 \%)$ and four levels of true digestible lysine $(0.7 ; 0.9 ; 1.1$ and $1.3 \%)$ with correction of the values for methionine and threonine following the ideal protein concept. At the final of experiment, one animal (experimental unit) of each treatment was slaughtered and the $\mathrm{pH}$ of estomacal and cecal contents, weight relative of the liver, pancreas and kidney and height of villous and crypts depth of jejune were taken. In the Experiment II, 32 barrows (initial weight $=25 \pm 1.3 \mathrm{~kg}$ ) proceeding from previous experiment, were allotted individually in metabolism cages (experimental unit) in RBD in time, in 2x4 factorial scheme (CP $x$ LYSD) with four repetitions in order to evaluate the nitrogen intake (NI), absorbed nitrogen (AN), retained nitrogen (RN) and NR/ NA relations (\%). There were no differences for the slaughtered variables analyzed. In the NR there was linear increasing effect $(\mathrm{P}<0.01)$ of the DLys levels in NI and quadratic effect $(\mathrm{P}<0.01)$ for RN and RN/AN, that showed increase until 1.05 and $1.06 \%$ DLys levels, respectively, independent of the $\mathrm{CP}$ levels. There were no differences $(\mathrm{P}>0.05)$ for $\mathrm{AN}$ for any treatments studied. It was conclude that the DLys and CP levels had any effect on organs weight, physiologic parameters and jejune morphometry, but they improve N Retention up to $25 \%$ with $1.05 \%$ of DLys in diets with reduced levels of CP.
\end{abstract}

Index terms: Amino acids, physiology, nutrition, ideal protein.

(Recebido em 3 de abril de 2006 e aprovado em 26 de janeiro de 2007)

\footnotetext{
${ }_{1}^{1}$ Parte da tese de Doutorado apresentada à Universidade Federal de Lavras/UFLA pelo primeiro autor.

${ }^{2}$ Doutor em Nutrição de Monogástricos - Departamento de Zootecnia/DZO - Universidade Federal de Lavras/UFLA - Cx. P. 3037 - $37200-000$ Lavras, MG - marciozan78@yahoo.com.br

${ }^{3}$ Professores do Departamento de Zootecnia/DZO - Universidade Federal de Lavras/UFLA - Cx. P. 3037 - 37200-000 - Lavras, MG - fialho@ufla.br ${ }^{4}$ Professor do Departamento de Medicina Veterinária/DMV - Universidade Federal de Lavras/UFLA - Cx. P. 3037 - $37200-000$ - Lavras, MG Ismurgas@ufla.br

${ }_{5}^{5}$ Mestranda em Nutrição de Monogástricos - Universidade Federal de Lavras/UFLA - Cx. P. 3037 - 37200-000 - Lavras, MG - erikavhr@yahoo.com.br

${ }^{6}$ Aluna do curso de Zootecnia - Universidade Federal de Lavras/UFLA - Cx. P. 3037 - 37200-000 - Lavras, MG - renatazootec@yahoo.com.br
} 


\section{INTRODUÇÃO}

A utilização de conceitos modernos na alimentação animal, dentre eles, o uso do conceito de proteína ideal através da adição de aminoácidos sintéticos, tem sido largamente preconizado, em função do melhor aproveitamento dos nutrientes dietéticos em especial o nitrogênio, e à menor excreção desse elemento nos dejetos dos suínos. No entanto, alguns efeitos da manipulação dos níveis protéicos da dieta têm sido associados a algumas alterações morfológicas e fisiológicas, em especial em suínos na fase inicial.

Durante o desmame, os leitões apresentam o trato digestório ainda imaturo, representado pela menor eficiência em digerir alimentos de origem protéica, principalmente devido à menor produção de ácido clorídrico no estômago e baixa atividade das enzimas pancreáticas e intestinais (PROHÁSZKA \& BARÓN, 1987), interferindo diretamente na digestibilidade dos nutrientes, em especial os aminoácidos presentes na dieta (GÓMEZ et al., 2002). Além disso, a presença de fatores alergênicos presentes em diversos alimentos, dentre eles o farelo de soja, tem sido associado à redução da altura de vilosidades e hiperplasia das criptas, em virtude da agressão à mucosa intestinal e ativação do sistema imune local (HOUDIJK et al., 1999).

A possibilidade de manipulação dos níveis protéicos na ração através da redução da proteína bruta e suplementação com aminoácidos cristalinos supõe a necessidade de se verificar os efeitos dessa prática nos parâmetros morfológicos e fisiológicos de leitões na fase inicial e a influência desses fatores na digestibilidade do nitrogênio presente nas rações.

\section{MATERIAL E MÉTODOS}

Dois experimentos foram conduzidos no Setor de Suinocultura do Departamento de Zootecnia da Universidade Federal de Lavras, em Lavras, Minas Gerais.

No experimento I, foram utilizados 80 suínos mestiços (Landrace x Large White) machos castrados e fêmeas, desmamados aos 28 dias, com peso médio inicial de $9,1 \pm 1,2 \mathrm{~kg}$ e final de $21,5 \pm 4,8 \mathrm{~kg}$, alojados em sala de alvenaria, no galpão de creche, em grupos de dois animais, mantidos em baias suspensas $(2,00 \times 1,20 \mathrm{~m})$ a $1,20 \mathrm{~m}$ de altura, com piso ripado, dotadas de comedouros semiautomáticos e bebedouro tipo chupeta, durante um período experimental de 35 dias. $\mathrm{O}$ ambiente foi semi-controlado com lâmpadas para aquecimento e ventiladores, sendo a temperatura mantida entre $20^{\circ} \mathrm{C}$ e $25^{\circ} \mathrm{C}$.
As rações e a água foram fornecidas à vontade. Os tratamentos consistiram em oito dietas experimentais isocalóricas e isonutritivas, formuladas à base de milho, farelo de soja, leite em pó e farelo de glúten, de acordo com Rostagno et al. (2000) para suínos na fase inicial, sendo dois níveis de proteína bruta $(16$ e $18 \%$ ) e quatro níveis de lisina digestível verdadeira $(0,7 ; 0,9 ; 1,1$ e $1,3 \%)$. As dietas experimentais são apresentadas na Tabela 1 .

Ao final do experimento, um animal de cada tratamento foi abatido e imediatamente mensurados o $\mathrm{pH}$ do conteúdo estomacal e cecal usando um medidor de pH F-1003 Bernauer $^{\circledR}$. Em seguida, foram coletadas amostras do terço médio do jejuno, que foram armazenadas em solução Boin (solução aquosa saturada de ácido pícrico, formol e ácido acético) por 24 horas e posteriormente em álcool $70 \%$ até as confecções dos cortes, de acordo com a metodologia de Junqueira \& Junqueira (1983), para a avaliação da altura de vilosidades e de profundidade de criptas em microscópio óptico em aumento de 200 vezes. O fígado, o pâncreas e os rins foram retirados e determinados os respectivos pesos em relação ao peso vivo do animal.

No experimento II, 32 suínos machos castrados (peso inicial $=25 \pm 1,3 \mathrm{~kg}$ ), provenientes do experimento anterior, foram alojados individualmente em sala climatizada em gaiolas de metabolismo para avaliar o balanço de $\mathrm{N}$ das rações experimentais. O período experimental foi de nove dias, sendo cinco para adaptação dos animais e quatro para coleta total de fezes e de urina. As rações foram fornecidas de acordo com o peso metabólico de cada animal $\left(\mathrm{PV}^{0,75}\right)$, sendo o óxido férrico utilizado para se definir o início e o final da coleta de fezes, segundo a metodologia descrita por Fialho et al. (1979). Foram analisados o nitrogênio ingerido (NI), o nitrogênio absorvido (NA), o nitrogênio retido (NR) e a relação NR/NA.

Para as análises estatísticas dos experimentos, foi adotado um delineamento em blocos ao acaso com oito tratamentos em esquema fatorial 2 x 4 (dois níveis de PB e quatro níveis de lisina digestível verdadeira), sendo quatro repetições para o balanço de nitrogênio e cinco para as demais variáveis. Em todos os casos, os blocos foram constituídos pelos diferentes tempos de início do experimento. A unidade experimental foi representada por um animal.

Todas as análises estatísticas foram realizadas no pacote estatístico SISVAR, descrito por Ferreira (2000), sendo os dados submetidos ao teste $\mathrm{F}$, submetidos à análise de regressão e ao desdobramento da interação proteína bruta $\mathrm{x}$ lisina quando significativo. 
TABELA 1 - Composição percentual e química das dietas experimentais.

\begin{tabular}{|c|c|c|c|c|c|c|c|c|}
\hline \multirow{3}{*}{ Ingrediente } & \multicolumn{8}{|c|}{ Dieta Experimental } \\
\hline & \multicolumn{4}{|c|}{$18 \% \mathrm{~PB}$} & \multicolumn{4}{|c|}{$16 \%$ PB } \\
\hline & $\begin{array}{c}0,7 \% \\
\text { lis }\end{array}$ & $\begin{array}{l}0,9 \% \\
\text { lis }\end{array}$ & $\begin{array}{l}1,1 \% \\
\text { lis }\end{array}$ & $\begin{array}{l}1,3 \% \\
\text { lis }\end{array}$ & $\begin{array}{l}0,7 \% \\
\text { lis }\end{array}$ & $\begin{array}{c}\mathbf{0 , 9 \%} \\
\text { lis }\end{array}$ & $\begin{array}{c}1,1 \% \\
\text { lis }\end{array}$ & $\begin{array}{l}1,3 \% \\
\text { lis }\end{array}$ \\
\hline Milho & 59,00 & 59,00 & 59,00 & 59,00 & 59,00 & 59,00 & 59,00 & 59,00 \\
\hline Farelo de soja & 20,00 & 20,00 & 20,00 & 20,00 & 15,60 & 15,6 & 15,60 & 15,60 \\
\hline Farelo de gluten & 4,20 & 4,20 & 4,20 & 4,20 & 4,20 & 4,20 & 4,20 & 4,20 \\
\hline Óleo de soja & 1,90 & 1,90 & 1,90 & 1,90 & 1,90 & 1,90 & 1,90 & 1,90 \\
\hline Leite em pó modificado & 5,00 & 5,00 & 5,00 & 5,00 & 5,00 & 5,00 & 5,00 & 5,00 \\
\hline Amido de mandioca & 4,60 & 4,60 & 4,60 & 4,60 & 8,60 & 8,60 & 8,60 & 8,60 \\
\hline Fosf. Bicálcico & 1,63 & 1,63 & 1,63 & 1,63 & 1,68 & 1,68 & 1,68 & 1,68 \\
\hline Calcário calcítico & 0,80 & 0,80 & 0,80 & 0,80 & 0,80 & 0,80 & 0,80 & 0,80 \\
\hline Sal iodado & 0,30 & 0,30 & 0,30 & 0,30 & 0,30 & 0,30 & 0,30 & 0,30 \\
\hline Premix vitamínico ${ }^{1}$ & 0,10 & 0,10 & 0,10 & 0,10 & 0,10 & 0,10 & 0,10 & 0,10 \\
\hline Premix mineral $^{2}$ & 0,10 & 0,10 & 0,10 & 0,10 & 0,10 & 0,10 & 0,10 & 0,10 \\
\hline L-Lisina $\mathrm{HCl} 78 \%$ & 0,00 & 0,28 & 0,56 & 0,85 & 0,15 & 0,43 & 0,72 & 1,00 \\
\hline DL-Metionina $98 \%$ & 0,00 & 0,00 & 0,05 & 0,12 & 0,00 & 0,02 & 0,08 & 0,14 \\
\hline L-Treonina & 0,00 & 0,011 & 0,14 & 0,28 & 0,00 & 0,08 & 0,21 & 0,34 \\
\hline Bacitracina de zinco & 0,03 & 0,03 & 0,03 & 0,03 & 0,03 & 0,03 & 0,03 & 0,03 \\
\hline Caulim & 2,30 & 1,90 & 1,30 & 0,70 & 2,30 & 1,80 & 1,20 & 0,50 \\
\hline Bicarbonato de sódio & 0,00 & 0,13 & 0,26 & 0,39 & 0,25 & 0,38 & 0,52 & 0,65 \\
\hline \multicolumn{9}{|c|}{ Valor Calculado } \\
\hline $\begin{array}{l}\text { Energia digestível } \\
(\mathrm{Kcal} / \mathrm{Kg})\end{array}$ & 3401 & 3401 & 3401 & 3401 & 3414 & 3414 & 3414 & 3414 \\
\hline $\begin{array}{l}\text { Energia metabolizável } \\
(\mathrm{Kcal} / \mathrm{Kg})\end{array}$ & 3154 & 3154 & 3154 & 3154 & 3172 & 3172 & 3172 & 3172 \\
\hline Proteína Bruta (\%) & 18,00 & 18,00 & 18,00 & 18,00 & 16,00 & 16,00 & 16,00 & 16,00 \\
\hline Cálcio (\%) & 0,83 & 0,83 & 0,83 & 0,83 & 0,82 & 0,82 & 0,82 & 0,82 \\
\hline Fósforo Disponível (\%) & 0,43 & 0,43 & 0,43 & 0,43 & 0,42 & 0,42 & 0,42 & 0,42 \\
\hline Lisina digestível (\%) & 0,70 & 0,90 & 1,10 & 1,30 & 0,70 & 0,90 & 1,10 & 1,30 \\
\hline
\end{tabular}

${ }^{1}$ Suplemento vitamínico contendo: vitamina A, 8.000.000 UI; vitamina $\mathrm{D}_{3}, 1.200 .000 \mathrm{UI}$; vitamina E, $20 \mathrm{~g}$; vitamina $\mathrm{K}_{3}, 2.500 \mathrm{mg}$; vitamina $B_{1}, 1.000 \mathrm{mg}$; riboflavina $\left(B_{2}\right), 4.000 \mathrm{mg}$; piridoxina $\left(B_{6}\right), 2.000 \mathrm{mg}$; vitamina $B_{12}, 20.000$ mcg; niacina, $25.000 \mathrm{mg}$; ácido pantotênico, $10 \mathrm{~g}$; ácido fólico, $600 \mathrm{mg}$; biotina, $50 \mathrm{mg}$; vitamina C, $50 \mathrm{~g}$; antioxidante, $125 \mathrm{mg}$ e excipiente q.s.q. $1000 \mathrm{~g}$.

${ }^{2}$ Suplemento Mineral contendo, por Kg do produto: selênio, $500 \mathrm{mg}$; ferro, $180 \mathrm{~g}$; cobre, $20 \mathrm{~g}$; manganês, $80 \mathrm{~g}$; zinco, $140 \mathrm{~g}$; iodo, $4 \mathrm{~g}$; cobalto, $4 \mathrm{~g}$ e excipiente q.s.q. $1000 \mathrm{~g}$

\section{RESULTADOS E DISCUSSÃO}

Os resultados para pH do estômago e do ceco estão apresentados na Tabela 2. Não houve efeito dos tratamentos nestas variáveis $(\mathrm{P}>0,05)$. Os resultados confirmam os obtidos por Li et al. (1990). Segundo esses autores, suínos a partir da quinta semana de vida já estão aptos a digerir grande parte da fração protéica da dieta. Por outro lado, a redução do farelo de soja em rações com $16 \%$ PB podem não ter sido suficientes para provocar alterações nestes parâmetros. Além disso, tem-se verificado resultados controversos na literatura a respeito de medidas de $\mathrm{pH}$ do estômago e do ceco em função da região onde são feitas as determinações, do tipo de técnica utilizada e do tempo após a ingestão de alimentos.

Com relação ao peso relativo de órgãos, os valores estão apresentados na Tabela 3. Não houve efeito dos níveis de lisina e PB na dieta sobre essas variáveis $(\mathrm{P}>0,05)$. Resultados semelhantes para peso do fígado e do pâncreas foram obtidos por Kerr et al. (2003), ao trabalharem com níveis diferenciados de PB em rações suplementadas ou não com aminoácidos cristalinos. Segundo Rao \& McCracken (1992), o peso dos órgãos deveria variar em função do consumo de energia e/ou proteína, sugerindo que, mantidas as mesmas quantidades desses fatores, os pesos seriam semelhantes. 
O fígado é um dos principais locais de degradação de aminoácidos e metabolismo de nitrogênio. Santiago et al. (2005) observaram maior peso do fígado em suínos na fase inicial ao trabalharem com níveis crescentes de PB na ração $(17,19,21$ e $23 \%)$.

Com relação ao peso do pâncreas, Chen et al. (1995) observaram uma redução no peso desse órgão em função dos níveis decrescentes de PB na ração. De acordo com esses autores, a maior produção de enzimas proteolíticas estimuladas pela presença de proteínas intactas no trato digestório seria a responsável por esse aumento. Provavelmente os níveis desse nutriente propostos neste experimento não foram suficientes para afetar esta variável.

TABELA 2 - pH do estômago e do ceco de leitões aos 20 kg recebendo rações com diferentes níveis de proteína bruta e lisina digestível ${ }^{1}$.

\begin{tabular}{|c|c|c|c|c|c|}
\hline \multicolumn{6}{|c|}{ pH Estomago } \\
\hline \multirow{2}{*}{ Proteína bruta (\%) } & \multicolumn{4}{|c|}{ Nível de lisina (\%) } & \multirow{2}{*}{ Média } \\
\hline & $\mathbf{0 , 7}$ & $\mathbf{0 , 9}$ & 1,1 & 1,3 & \\
\hline 16 & 3,67 & 3,32 & 2,73 & 3,12 & 3,21 \\
\hline 18 & 3,27 & 3,13 & 3,07 & 3,19 & 3,17 \\
\hline Média & 3,47 & 3,23 & 2,90 & 3,16 & \\
\hline $\mathrm{CV}(\%)$ & 20,73 & & & & \\
\hline \multicolumn{6}{|c|}{ pH Ceco } \\
\hline \multirow{2}{*}{ Proteína bruta (\%) } & \multicolumn{4}{|c|}{ Nível de lisina (\%) } & Média \\
\hline & $\mathbf{0 , 7}$ & 0,9 & 1,1 & 1,3 & vieala \\
\hline 16 & 5,91 & 5,72 & 5,67 & 5,95 & 5,81 \\
\hline 18 & 5,89 & 5,98 & 5,79 & 5,58 & 5,81 \\
\hline Média & 5,90 & 5,85 & 5,73 & 5,77 & \\
\hline $\mathrm{CV}(\%)$ & 7,18 & & & & \\
\hline
\end{tabular}

${ }^{1}$ Não houve diferenças significativas pelo teste $\mathrm{F}(\mathrm{P}>0,05)$.

TABELA 3 - Peso relativo do fígado, pâncreas e dos rins de leitões aos 20 kg recebendo rações com diferentes níveis de proteína bruta e lisina digestível ${ }^{1}$.

\begin{tabular}{|c|c|c|c|c|c|}
\hline \multicolumn{6}{|c|}{ Peso do Fígado ( $\%$ peso vivo) } \\
\hline \multirow{2}{*}{$\begin{array}{c}\text { Proteína Bruta } \\
(\%)\end{array}$} & \multicolumn{4}{|c|}{ Nível de lisina (\%) } & \multirow[b]{2}{*}{ Média } \\
\hline & $\mathbf{0 , 7}$ & $\mathbf{0 , 9}$ & 1,1 & 1,3 & \\
\hline 16 & 2,95 & 2,88 & 2,91 & 2,89 & 2,91 \\
\hline 18 & 2,98 & 2,96 & 2,90 & 2,96 & 2,95 \\
\hline Média & 2,97 & 2,92 & 2,91 & 2,93 & \\
\hline \multirow[t]{2}{*}{$\mathrm{CV}(\%)$} & 10,89 & & & & \\
\hline & \multicolumn{4}{|c|}{ Peso do Pâncreas (\% peso vivo) } & \\
\hline \multirow{2}{*}{$\begin{array}{c}\text { Proteína Bruta } \\
(\%)\end{array}$} & \multicolumn{4}{|c|}{ Nível de lisina (\%) } & \multirow{2}{*}{ Média } \\
\hline & 0,7 & $\mathbf{0 , 9}$ & 1,1 & 1,3 & \\
\hline 16 & 0,262 & 0,254 & 0,256 & 0,254 & 0,250 \\
\hline 18 & 0,254 & 0,260 & 0,252 & 0,232 & 0,257 \\
\hline Média & 0,258 & 0,257 & 0,254 & 0,243 & \\
\hline $\mathrm{CV}(\%)$ & 11,76 & & & & \\
\hline \multicolumn{6}{|c|}{ Peso dos Rins (\% peso vivo) } \\
\hline \multirow{2}{*}{$\begin{array}{c}\text { Proteína Bruta } \\
(\%)\end{array}$} & \multicolumn{4}{|c|}{ Nível de lisina (\%) } & \multirow[b]{2}{*}{ Média } \\
\hline & 0,7 & 0,9 & 1,1 & 1,3 & \\
\hline 16 & 0,470 & 0,470 & 0,448 & 0,454 & 0,460 \\
\hline 18 & 0,442 & 0,452 & 0,468 & 0,458 & 0,455 \\
\hline Média & 0,456 & 0,461 & 0,458 & 0,456 & \\
\hline $\mathrm{CV}(\%)$ & 13,20 & & & & \\
\hline
\end{tabular}

${ }^{1}$ Não houve diferenças significativas pelo teste $\mathrm{F}(\mathrm{P}>0,05)$. 
Com relação ao peso dos rins, Kerr et al. (2003) e Santiago et al. (2005) constataram maior peso dos rins em animais que receberam rações contendo maiores níveis de PB. Segundo Chen et al. (1995), os rins, juntamente com o fígado, são os principais órgãos relacionados ao metabolismo do $\mathrm{N}$, exercendo um papel importante na regulação dos níveis de aminoácidos no plasma. Entretanto, há estudos em que o consumo desses nutrientes não modificou o peso desses órgãos em suínos (LE-BELLEGO et al., 2002).

De uma forma geral, o tempo experimental (35 dias) pode não ter sido suficiente para se obter diferenças significativas entre os pesos dos órgãos neste experimento. Gómez et al. (2002) evidenciam uma tendência a longo prazo do efeito da dieta sobre essas variáveis.

Os resultados para altura de vilosidades, profundidade de criptas e relação vilosidade : cripta são encontrados na Tabela 4.
Da mesma forma, não houve efeito dos níveis de PB e dos níveis de lisina sobre estas variáveis $(\mathrm{P}>0,05)$. Os dados evidenciam mais uma vez que não houve alterações do padrão fisiológico do trato digestório dos leitões aos 35 dias de creche. $\mathrm{Na}$ literatura, poucos trabalhos têm associado essas variáveis com adição de aminoácidos cristalinos na dieta para suínos. Além da redução do fator alergênico proporcionado pelo farelo de soja, estudos conduzidos com cobaias evidenciam que rações formuladas com esses aminoácidos de forma excessiva resultam em atrofia intestinal e perda da permeabilidade do intestino, além de reduzir a retenção de $\mathrm{N}$ e o crescimento dos animais (BIRKE et al., 1990). Estes autores argumentam que o uso destas substâncias nas rações impede a utilização de aminoácidos específicos pelos enterócitos, uma vez que são rapidamente absorvidos na porção inicial do intestino delgado. Zangeronimo et al. (2004a) também não observaram diferenças nestes parâmetros ao trabalharem com níveis reduzidos de PB e farelo de soja com suplementação de aminoácidos na dieta para leitões nas três primeiras semanas pós-desmame.

TABELA 4 - Altura de vilosidades, profundidade de criptas e relação vilosidade : cripta do jejuno de leitões aos $20 \mathrm{~kg}$ recebendo rações com diferentes níveis de proteína bruta e lisina digestível ${ }^{1}$.

\begin{tabular}{|c|c|c|c|c|c|}
\hline \multicolumn{6}{|c|}{ Altura de Vilosidades $(\mu \mathrm{m})$} \\
\hline \multirow{2}{*}{$\begin{array}{c}\text { Proteína Bruta } \\
(\%)\end{array}$} & \multicolumn{4}{|c|}{ Nível de lisina $(\%)$} & \multirow[b]{2}{*}{ Média } \\
\hline & 0,7 & 0,9 & 1,1 & 1,3 & \\
\hline 16 & 498 & 472 & 517 & 485 & 493 \\
\hline 18 & 500 & 490 & 456 & 453 & 475 \\
\hline Média & 499 & 481 & 486 & 470 & \\
\hline $\mathrm{CV}(\%)$ & 15,09 & & & & \\
\hline \multicolumn{6}{|c|}{ Profundidade de Criptas $(\mu \mathrm{m})$} \\
\hline \multirow{2}{*}{$\begin{array}{c}\text { Proteína Bruta } \\
(\%)\end{array}$} & \multicolumn{4}{|c|}{ Nível de lisina (\%) } & \multirow{2}{*}{ Média } \\
\hline & $\mathbf{0 , 7}$ & $\mathbf{0 , 9}$ & 1,1 & 1,3 & \\
\hline 16 & 287 & 299 & 292 & 285 & 281 \\
\hline 18 & 300 & 283 & 272 & 269 & 291 \\
\hline Média & 294 & 289 & 283 & 277 & \\
\hline $\mathrm{CV}(\%)$ & 17,02 & & & & \\
\hline \multicolumn{6}{|c|}{ Relação Vilosidade : Cripta } \\
\hline \multirow{2}{*}{$\begin{array}{c}\text { Proteína Bruta } \\
(\%)\end{array}$} & \multicolumn{4}{|c|}{ Nível de lisina $(\%)$} & \multirow{2}{*}{ Média } \\
\hline & 0,7 & 0,9 & 1,1 & 1,3 & \\
\hline 16 & 1,74 & 1,58 & 1,77 & 1,71 & 1,70 \\
\hline 18 & 1,68 & 1,76 & 1,70 & 1,70 & 1,71 \\
\hline Média & 1,71 & 1,67 & 1,73 & 1,70 & \\
\hline $\mathrm{CV}(\%)$ & 10,0 & & & & \\
\hline
\end{tabular}

\footnotetext{
${ }^{1}$ Não houve diferenças significativas pelo teste $\mathrm{F}(\mathrm{P}>0,05)$.
} 
Os resultados obtidos para balanço de $\mathrm{N}$ dos leitões na fase inicial estão apresentados na Tabela 5.

Não houve interação ( $\mathrm{P}>0,05)$ entre níveis de lisina e $\mathrm{PB}$ na dieta para $\mathrm{N}$ ingerido pelos animais. Os resultados mostram um aumento linear significativo $(\mathrm{P}<0,01)$ para esta variável em função do aumento dos níveis de lisina na dieta e uma diferença $(\mathrm{P}<0,01)$ entre os níveis de $\mathrm{PB}$ utilizados.
Com relação ao nitrogênio absorvido, não houve diferenças entre os tratamentos $(\mathrm{P}>0,05)$. Shriver et al. (2003) também não observaram diferenças para estas variáveis ao reduzirem a PB da ração em quatro unidades percentuais para animais em crescimento. A partir desses resultados, supõe-se que a diferença na velocidade de absorção entre aminoácidos de origem cristalina e os aminoácidos

TABELA 5 - Balanço de nitrogênio de leitões aos $25 \mathrm{~kg}$ recebendo rações com diferentes níveis de proteína bruta e lisina digestível.

\begin{tabular}{|c|c|c|c|c|c|}
\hline \multicolumn{6}{|c|}{ Nitrogênio Ingerido (g/dia) } \\
\hline \multirow{2}{*}{$\begin{array}{c}\text { Proteína Bruta } \\
(\%)\end{array}$} & \multicolumn{4}{|c|}{ Nível de lisina (\%) } & \multirow{2}{*}{ Média } \\
\hline & 0,7 & 0,9 & 1,1 & 1,3 & \\
\hline 16 & 23,23 & 24,18 & 24,90 & 26,14 & $24,63 \mathrm{~B}$ \\
\hline 18 & 24,16 & 24,86 & 25,86 & 26,70 & $25,40 \mathrm{~A}$ \\
\hline Média $^{2}$ & 23,72 & 24,53 & 25,38 & 26,42 & \\
\hline $\mathrm{CV}(\%)$ & 1,53 & & & & \\
\hline \multicolumn{6}{|c|}{ Nitrogênio Absorvido (\%) } \\
\hline \multirow{2}{*}{$\begin{array}{c}\text { Proteína Bruta } \\
(\%)\end{array}$} & \multicolumn{4}{|c|}{ Nível de lisina $(\%)$} & \multirow{2}{*}{ Média } \\
\hline & 0,7 & $\mathbf{0 , 9}$ & 1,1 & 1,3 & \\
\hline 16 & 85,90 & 85,60 & 86,44 & 85,38 & 85,83 \\
\hline 18 & 85,80 & 86,02 & 85,84 & 84,98 & 85,66 \\
\hline Média & 85,85 & 85,81 & 86,14 & 85,18 & \\
\hline $\mathrm{CV}(\%)$ & 2,52 & & & & \\
\hline \multicolumn{6}{|c|}{ Nitrogênio Retido (\%) } \\
\hline \multirow{2}{*}{$\begin{array}{c}\text { Proteína Bruta } \\
(\%)\end{array}$} & \multicolumn{4}{|c|}{ Nível de lisina (\%) } & \multirow{2}{*}{ Média $^{1}$} \\
\hline & $\mathbf{0 , 7}$ & $\mathbf{0 , 9}$ & 1,1 & 1,3 & \\
\hline 16 & 58,38 & 69,24 & 68,72 & 65,76 & $65,53 \mathrm{~A}$ \\
\hline 18 & 58,40 & 62,78 & 62,72 & 60,22 & $61,03 \mathrm{~B}$ \\
\hline Média $^{3}$ & 58,39 & 66,01 & 65,72 & 62,99 & \\
\hline $\mathrm{CV}(\%)$ & 7,80 & & & & \\
\hline \multicolumn{6}{|c|}{ Nitrogênio Retido / Nitrogênio Absorvido (\%) } \\
\hline \multirow{2}{*}{$\begin{array}{c}\text { Proteína Bruta } \\
(\%)\end{array}$} & \multicolumn{4}{|c|}{ Nível de lisina (\%) } & \multirow{2}{*}{ Média $^{1}$} \\
\hline & 0,7 & 0,9 & 1,1 & 1,3 & \\
\hline 16 & 67,9 & 80,8 & 79,5 & 77,0 & $76,3 \mathrm{~A}$ \\
\hline 18 & 68,1 & 72,9 & 73,0 & 70,8 & $71,2 \mathrm{~B}$ \\
\hline Média $^{4}$ & 68,0 & 76,9 & 76,3 & 73,9 & \\
\hline $\mathrm{CV}(\%)$ & 6,22 & & & & \\
\hline
\end{tabular}

${ }^{1}$ Médias seguidas por letras maiúsculas diferentes na coluna diferem pelo teste $\mathrm{F}(\mathrm{P}<0,01)$

${ }^{2}$ Efeito quadrático significativo $(\mathrm{P}<0,01): \mathrm{y}=4,475 \mathrm{x}+20,537 ; \mathrm{R}^{2}=0,996$

${ }^{3}$ Efeito quadrático significativo $(\mathrm{P}<0,01): \mathrm{y}=-64,688 \mathrm{x}^{2}+136,13 \mathrm{x}-4,9306 ; \mathrm{R}^{2}=0,96$

${ }^{4}$ Efeito quadrático significativo $(\mathrm{P}<0,01)$ : $\mathrm{y}=-70,625 \mathrm{x}^{2}+149,8 \mathrm{x}-1,8688 ; \mathrm{R}^{2}=0,94$ 
provenientes dos alimentos não interfere na passagem destes nutrientes do trato gastrintestinal para o sangue.

Quanto ao N retido, não houve efeito da interação entre níveis de lisina e PB na dieta $(\mathrm{P}>0,05)$. No entanto, houve efeito quadrático para níveis de lisina $(\mathrm{P}<0,01)$ e maior retenção pelos animais que consumiram $16 \%$ PB $(\mathrm{P}<0,01)$. Resultados semelhantes com níveis reduzidos de PB na ração são encontrados na literatura com animais na fase inicial (ZANGERONIMO et al., 2004b) e em crescimento (OLIVEIRA, 2004).

No presente trabalho, o nível de lisina digestível que proporcionou maior retenção de $\mathrm{N}$ pelos animais foi de 1,05 $\%$, com taxa de retenção máxima de $66,7 \%$ (Figura 1 ). No entanto, a possibilidade da inclusão de outros aminoácidos como o triptofano, valina, leucina e isoleucina, por exemplo, podem afetar esse nível obtido. Além disso, a variação dos níveis de lisina digestível verdadeira de 0,7 a $1,3 \%$ proporcionou uma diferença na retenção de $\mathrm{N}$ em $12 \%$, evidenciando a importância em se manipular os teores deste aminoácido nas rações.

Com relação à porcentagem de $\mathrm{N}$ retido em relação ao que foi absorvido (NRET/NABS), não houve efeito da interação dos níveis de lisina com os níveis de $\mathrm{PB}$ na dieta $(\mathrm{P}>0,05)$, porém houve maior eficiência $(\mathrm{P}<0,01)$ da utilização do $\mathrm{N}$ em rações contendo maiores níveis de aminoácidos cristalinos (16\% PB) e efeito quadrático significativo $(\mathrm{P}<0,01)$ para níveis de lisina digestível na ração, sendo $1,06 \%$ o nível que apresentou o melhor aproveitamento de $\mathrm{N}$ pelos animais (Figura 2). Entretanto, esta relação

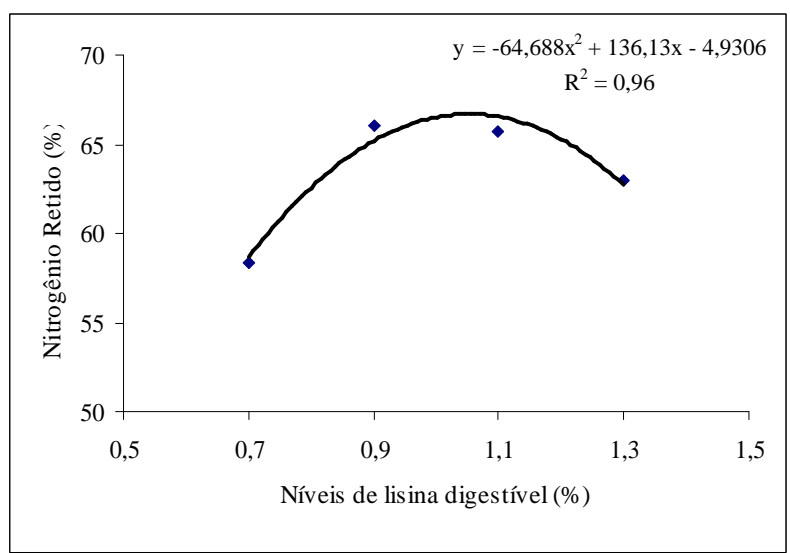

FIGURA 1 - Retenção de nitrogênio (\%) de leitões aos 25 $\mathrm{kg}$ recebendo rações com 16 e $18 \%$ de proteína bruta e níveis crescentes de lisina digestível verdadeira. pode ser alterada se adicionados outros aminoácidos essenciais na dieta, como anteriormente mencionado (OLIVEIRA, 2004).

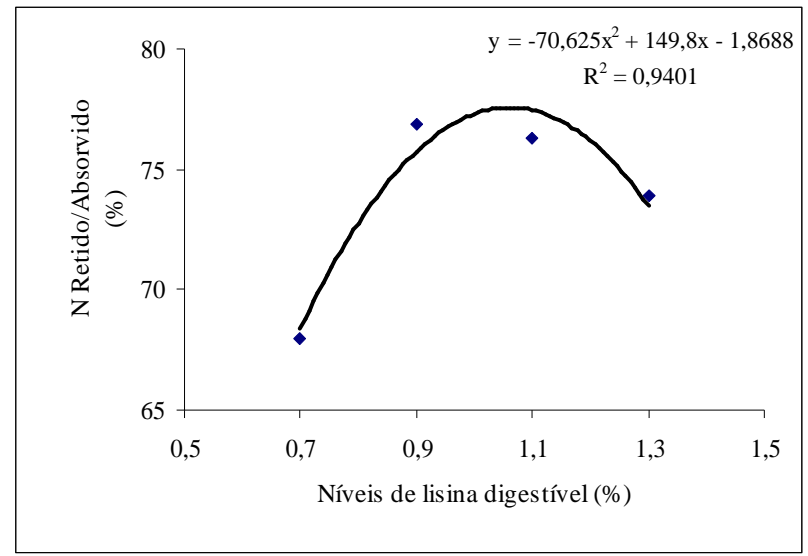

FIGURA 2 - Eficiência de utilização do nitrogênio absorvido por leitões aos $25 \mathrm{~kg}$ recebendo rações com 16 e $18 \%$ de proteína bruta e níveis crescentes de lisina digestível verdadeira.

Além disso, sugere-se que os níveis energéticos das dietas possam interferir no aproveitamento do $\mathrm{N}$ dietético, principalmente em rações com $16 \% \mathrm{~PB}$, onde o menor incremento calórico proporcionado por essas dietas pode ter levado a uma maior quantidade de energia líquida disponível para os animais. Neste caso, outros estudos devem ser conduzidos para se determinar a relação ideal entre os principais aminoácidos essenciais e os níveis energéticos em dietas contendo níveis reduzidos de $\mathrm{PB}$.

\section{CONCLUSÕES}

A manipulação dos níveis de proteína bruta e de lisina digestível na dieta não afetou o peso dos órgãos e tampouco os parâmetros fisiológicos e morfológicos do trato gastrintestinal de leitões na fase inicial. Entretanto, melhoraram a retenção de nitrogênio em até $25 \%$, com 1,05\% de lisina digestível verdadeira em dietas com níveis reduzidos de proteína bruta.

\section{REFERÊNCIAS BIBLIOGRÁFICAS}

BIRKE, H.; THORLACIUS-USSING, O.; HESSOV, I. Trophic effect of dietary peptides on mucosa in the rat small bowel. Journal Parenteral and Enteral Nutrition, Silver Spring, v. 14, p. 265, Aug. 1990. 
CHEN, H. Y.; MILLER, P. S.; LEWIS, A. J.; WOLVERTON, C. K.; STROUP, W. Changes in plasma urea concentration can be used to determine protein requirements of two populations of pigs with different protein accretion ration. Journal Animal Science, Champaign, v. 73, n. 9, p. 261-2639, Sept. 1995.

FERREIRA, D. F. Análises estatísticas por meio do Sisvar para Windows versão 4.0. In: REUNIÃO ANUAL DA REGIÃO BRASILEIRA DA SOCIEDADE INTERNACIONAL DE BIOMETRIA, 45., 2000, São Carlos, SP. Anais... São Carlos: UFSCar, 2000. p. 255-258.

FIALHO, E. T.; ROSTAGNO, H. S.; FONSECA, J. B.; SILVA, M. A. Efeito do peso vivo sobre o balanço energético e proteico de rações à base de milho e de sorgos com diferentes conteúdos de tanino para suínos. Revista da Sociedade Brasileira de Zootecnia, Viçosa, v. 8, n. 3, p. 386-397, 1979.

GÓMEZ, R. S.; LEWIS, A. J.; MILLER, P. S.; CHEN, H. Y. Growth performance, diet apparent digestibility and plasma metabolite concentrations of barrows fed corn-soybean meal diets or low-protein, amino acid-supplemented diets at different feeding levels. Journal Animal Science, Champaign, v. 80, n. 3, p. 644-653, Mar. 2002.

HOUDIJK, J. G. M.; BOSCH, M. W.; TAMMINGA, S. Apparent ileal and total-tract nutrient digestion by pigs as affected by dietary nondigestible oligossacarides. Journal Animal Science, Champaign, v. 77, p. 148-158, 1999.

JUNQUEIRA, L. C. U.; JUNQUEIRA, L. M. M. S. Técnicas básicas de citologia e histologia. São Paulo: USP, 1983. 123 p.

KERR, B. J.; YEN, J. T.; NIENABER, J. A.; EASTER, R. A. Influences of dietary protein level, amino acid supplementation and environmental temperature on performance, body composition, organ weights and total heat production of growing pigs. Journal Animal Science, Champaign, v. 81, n. 8, p. 1998-2007, Aug. 2003.

LE-BELLEGO, L.; MILGEN, J. van; NOBLET, J. Effect of high temperature and low-protein diets on performance of growing pigs. Journal Animal Science, Champaign, v. 80, n. 3, p. 691-701, Mar. 2002.

LI, D. F.; NELSSEN, J. L.; REDDY, P. G.; BLECHA, F.; HANCOCK, J. D.; ALLEE, G. L.; GOODBAND, R. D.; KLEMM, R. D. Transient hypersensitivity to soybean meal in the early-weaned pig. Journal Animal Science, Champaign, v. 68, n. 6, p. 1790-1799, June 1990.
OLIVEIRA, V. Influência de rações com baixos teores de proteína bruta no balanço de nitrogênio e retenção tecidual em suínos em crescimento. 2004. 98 p. Tese (Doutorado) - Universidade Federal de Lavras, Lavras, 2004.

PROHASZKA, L.; BARÓN, F. The predisposing role of high dietary protein supplies in enteropathogenic $E$. coli infections of weaned pigs. Zen. Vet., [S.1.], v. 27, n. 3, p. 222-232, 1987.

RAO, D. S.; McCRACKEN, K. J. Energy: protein interactions in growing boars on high genetic potential for lean growth: 1 effects on growth, carcass characteristics and organ weights. Animal Production, Edinburgh, v. 54, n. 1, p. 75-82, Feb. 1992.

ROSTAGNO, H. S.; ALBINO, L. F. T.; DONZELE, J. L.; GOMES, P. C.; FERREIRA, A. S.; OLIVEIRA, R. F.; LOPES, D. C.Tabelas brasileiras para aves e suínos: composição de alimentos e exigências nutricionais. Viçosa: UFV, 2000. 141 p.

SANTIAGO, A. L. S.; CARVALHO, L. E.; BASTOS, F. J. S.; ESPÍNDOLA, G. B.; OLIVEIRA, S. M. P.; KRONKA, R. N. Estudo de níveis protéicos crescentes sobre o peso corporal, peso da carcaça e órgãos de leitões de creche. In: CONGRESSO BRASILEIRO DE VETERINÁRIOS ESPECIALISTAS EM SUÍNOS, 12., 2005, Fortaleza, CE. Anais... Fortaleza: UFCE, 2005. CD-ROM.

SHRIVER, J. A.; CARTER, S. D.; SUTTON, A. L.; RICHERT, B. T.; SENNE, B. W.; PETTY, L. A. Effects of adding fiber sources to reduced-crude protein, amino acid-supplemented diets on nitrogen excretion, growth performance, and carcass traits of finishing pigs. Journal Animal Science, Champaign, v. 81, n. 2, p. 492-502, Feb. 2003.

ZANGERONIMO, M. G.; FIALHO, E. T.; MURGAS, L. D. S.; CANTARELLI, V. S.; VIEIRA NETO, J. Efeito da redução do farelo de soja na ração com base no conceito de proteína ideal sobre o peso de órgãos, morfometria duodenal e incidência de diarréia de leitões na fase de creche. In: CONGRESSO LATINO AMERICANO DE SUINOCULTURA, 2., 2004, Foz do Iguaçu, PR. Anais... Foz do Iguaçu: UFPR, 2004a.

ZANGERONIMO, M. G.; FIALHO, E. T.; FREITAS, R. T.; HESPANHOL, R.; COSTA, L. B.; ROCHA, E. V. H. Efeito da redução da proteína bruta de rações suplementadas com aminoácidos sobre a excreção de nitrogênio de suínos em crescimento. In: REUNIÃO ANUAL DA SOCIEDADE BRASILEIRA DE ZOOTECNIA, 41., 2004, Campo Grande, MS. Anais... Campo Grande: UFMS, 2004b. CD-ROM. 